\title{
Molecular identification of protozoal and bacterial organisms in domestic animals and their infesting ticks from north-eastern Algeria
}

\author{
Rima Sadeddine $^{\mathrm{a}, \mathrm{b}, 1}$, Adama Zan Diarra ${ }^{\mathrm{b}, \mathrm{c}, \mathrm{d}, 1}$, Maureen Laroche ${ }^{\mathrm{b}}$, Oleg Mediannikov ${ }^{\mathrm{c}, \mathrm{e}}$, \\ Souad Righi ${ }^{\mathrm{a}}$, Ahmed Benakhla ${ }^{\mathrm{a}}$, Handi Dahmana ${ }^{\mathrm{c}, \mathrm{e}}$, Didier Raoult ${ }^{\mathrm{c}, \mathrm{e}}$, Philippe Parola ${ }^{\mathrm{b}, \mathrm{c}, *}$ \\ ${ }^{a}$ Université Chadli Bendjdid, Département des Sciences Vétérinaires, El Tarf, 36000, Algeria \\ ${ }^{\mathrm{b}}$ Aix Marseille Univ, IRD, AP-HM, SSA, VITROME, Marseille, France \\ ${ }^{\mathrm{c}}$ IHU Méditerranée Infection, Marseille, France \\ ${ }^{\mathrm{d}}$ Department of Epidemiology of Parasitic Diseases, Malaria Research and Training Center, University of Science, Techniques and Technologies of Bamako, Bamako, Mali \\ ${ }^{\mathrm{e}}$ Aix Marseille Univ, IRD, AP-HM, MEPHI, Marseille, France
}

Keywords:

\section{Piroplamorida}

Ticks

Rickettsia

Babesia

Algeria

Theileria

\begin{abstract}
A B S T R A C T
A molecular survey was undertaken to determine the presence of protozoal and bacterial organisms in 120 ticks and 87 blood samples collected from mammals in north-eastern Algeria. Eight tick species were morphologically identified including 70 Rhipicephalus (Boophilus) annulatus, 23 Rhipicephalus bursa, five Rhipicephalus sanguineus sensu lato, 11 Hyalomma impeltatum, five Hyalomma scupense, two Hyalommma marginatum, one Hyalomma anatolicum and three Ixodes ricinus. Quantitative PCR screening of the ticks showed that Theileria annulata, "Candidatus Ehrlichia urmitei", Theileria buffeli and Anaplasma platys were detected in Rh. annulatus. Rickettsia massiliae and Anaplasma ovis were detected in Rh. sanguineus s.l. and Rh. bursa. Rickettsia aeschlimannii was detected in Hy. marginatum, Hy. scupense and Hy. impeltatum. Finally, "Candidatus Rickettsia barbariae" was detected in Rh. bursa. In the screening blood samples, Theileria equi, T.annulata, T. buffeli, Babesia bovis, Anaplasma marginale, A. ovis and Borrelia spp. were detected in cattle. Theileria ovis, T. annulata, and A. ovis were detected in sheep. In addition, $A$. ovis and T. equi were detected in goats and equidea respectively. In this study, T. equi and "Candidatus Rickettsia barbariae" were identified for the first time in Algeria as well as potential new species of Ehrlichia and Anaplasma.

Although molecular detection does not indicate vector/reservoir competence when investigating ticks removed from animals, this study expands the knowledge of the microorganisms detected in ticks in north-east of Algeria.
\end{abstract}

\section{Introduction}

Ticks are obligate hematophagous arthropods known to be important vectors of a wide variety of protozoa, fungi, bacteria, viruses and filarial worms of medical and veterinary importance (Aydin et al., 2015; Pereira et al., 2016; Remedio et al., 2015). In Algeria, Medi-terranean spotted fever caused by Rickettsia conorii conorii is known to be endemic, and other rickettsial pathogens have been detected in ticks, including Rickettsia aeschlimannii, Rickettsia massiliae, Rickettsia helve-tica, Rickettsia monacensis, Rickettsia slovaca, Rickettsia africae and Rickettsia sibirica mongolitimonae (Kernif et al., 2012). In addition, other tick-borne pathogens such as Borrelia spp., Anaplasma spp., and Coxiella burnetii, have also been detected in ticks and/or cattle (Aouadi et al.,
2017; Boucheikhchoukh et al., 2018; Dahmani et al., 2015; Leulmi et al., 2016; Rjeibi et al., 2016; Ziam et al., 2015). Very few studies have been conducted on Theileria spp. and Babesia spp. in cattle and ticks from Algeria (Aouadi et al., 2017; Ziam et al., 2015). These studies reported the presence of Theileria orientalis, T. annulata, T. ovis, Babesia ovis, and B. bovis in cattle and ticks (Aouadi et al., 2017; Ziam et al., 2015). These apicomplexan protozoa are causative agents of piroplasmoses which are among the most economically important haemoparasitic tick-borne diseases of ruminants worldwide (Adjou Moumouni et al., 2015; Aydin et al., 2015; Toma et al., 2017; Dib et al., 2008; Pereira et al., 2016).

The aim of this study was to update the repertoire of protozoan and bacterial diseases in domestic animals and their infesting ticks in

\footnotetext{
* Corresponding author at: IHU Méditerranée Infection, 19-21 Boulevard Jean Moulin, Marseille, France.

E-mail address: philippe.parola@univ-amu.fr (P. Parola).

${ }^{1}$ Equal contributors.
} 


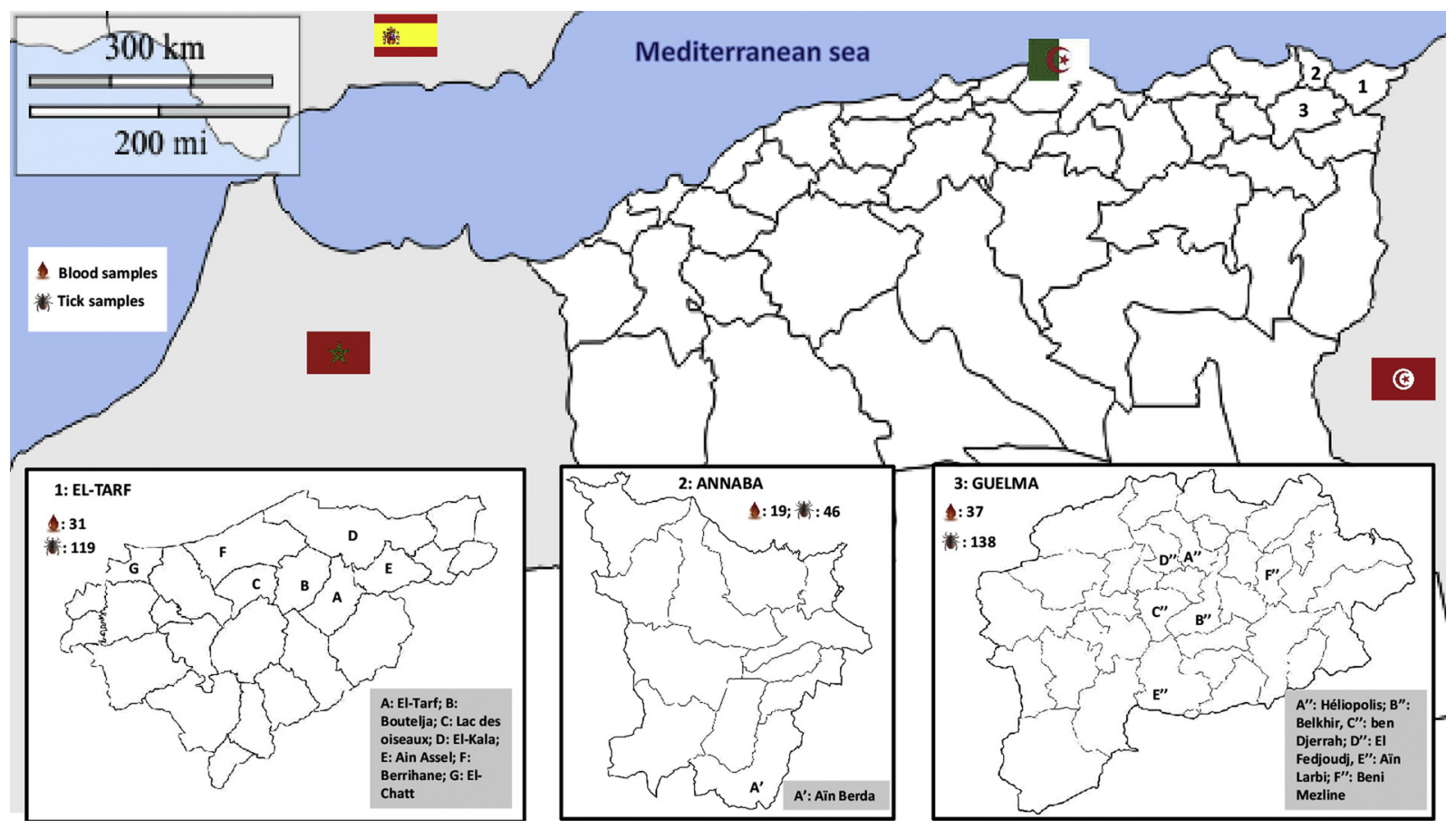

Fig. 1. Map of Algeria with sample collection sites.

northern Algeria, using molecular methods.

\section{Materials and methods}

\subsection{Study area, tick collection and blood sampling}

From March 2016 to February 2017, 303 ticks and 87 blood samples were collected from cattle in the provinces of Guelma $\left(36^{\circ} 27^{\prime} 0\right.$ "N $7^{\circ}$ $25^{\prime} 59.999 "$ E), Annaba ( $36^{\circ} 53$ ' $60^{\prime \prime} \mathrm{N} 7^{\circ} 46^{\prime} 0.001$ "E) and El-Tarf ( $36^{\circ}$ $46^{\prime} 1.2^{\prime \prime} \mathrm{N} 8^{\circ} 19$ '1.2 "E) in north-eastern Algeria (Fig. 1).

Blood samples were collected and stored in EDTA tubes at $-20^{\circ} \mathrm{C}$ and ticks were removed from animals and stored at room temperature in $70 \%$ ethanol. The morphological identification of ticks was carried out using a microscope and identification keys (Walker, 2003). The sample collection was authorised by the Animal Ethics Committee of ElTarf University (Law No. 88-08 of 26 January 1988 on the activities of veterinary medicine and the protection of animal health). Molecular analysis was performed on 120 selected ticks and all blood samples.

\subsection{Detection of microorganisms}

DNA was extracted individually from each sample (tick and blood) using the EZ1 DNA Tissue Kit (Qiagen, Hilden, Germany). Both sample types were screened by quantitative real-time PCR (qPCR) for Rickettsia spp., Bartonella spp., Anaplasmataceae spp., C. burnetii, Borrelia spp.,
Theileria spp. and Babesia spp., by using specific primers and probes (Table1). All the genus-qPCR positive samples for the different microorganisms were then tested using specific QPCR and/or subjected to standard PCR prior to sequencing to identify the microorganism species (Dahmani et al., 2015; Diarra et al., 2017; Tahir et al., 2016). Phylogenetic trees were drawn based on the alignment of the different genes using Bioedit and TOPALi 2.5 software (Biomathematics and Statistics Scotland, Edinburgh, United Kingdom) using the Tnr $+\Gamma$ substitution model. The nucleotide sequences were compared with GenBank entries using BLASTn and filed in GenBank under the following accession numbers: MH319801, MH327771, MH327772, MH327773, MH327774, MH321192, MH321193, MH321194, MH321195 and MH321197.

\section{Results}

\subsection{Tick identification and sample collection}

A total of 120 ticks belonging to eight species were morphologically collected and identified, including $R h$. annulatus, which was the most prevalent with $58.3 \%$ (70/120), followed by Rh. bursa (23/120), Hy. impeltatum with (11/120), Hy. scupense (5/120), I. ricinus (3/120), Rh. sanguineus s.l. (5/120), Hy. marginatum (2/120) and Hy. anatolicum (1/ 120) (Table 1). Of the 87 blood samples, 35, 27, 17 and 8 were collected from cattle, sheep, horses and goats respectively.

Table 1

Numbers of ticks used for pathogens identification.

\begin{tabular}{|c|c|c|c|c|c|}
\hline Tick species & Number collected from cattle & Number collected from sheep & Number collected from goats & Number collected from equidae & Total \\
\hline Rhipicephalus annulatus & 29 & 14 & 7 & 20 & 70 \\
\hline Rhipicephalus bursa & 0 & 14 & 9 & 0 & 23 \\
\hline Hyalomma impeltatum & 8 & 3 & 0 & 0 & 11 \\
\hline Hyalomma scupense & 0 & 1 & 4 & 0 & 5 \\
\hline Ixodes ricinus & 0 & 2 & 1 & 0 & 3 \\
\hline Rhipicephalus sanguineus s.l. & 0 & 2 & 3 & 0 & 5 \\
\hline Hyalomma marginatum & 0 & 1 & 1 & 0 & 2 \\
\hline Hyalomma anatolicum & 0 & 0 & 1 & 0 & 1 \\
\hline Total & 37 & 37 & 26 & 20 & 120 \\
\hline
\end{tabular}


Piroplasmorida were detected in seven (7/70; $10 \%) R h$. annulatus ticks and fourteen blood samples. Sequencing showed that six out of seven sequences obtained from ticks were $99.42 \%$ identical to T. annulata (KX273857) and one was $99.24 \%$ identical to T. buffeli (HM538197). For the blood samples the sequencing showed that five of fourteen sequences were $99.15-99.89 \%$ identical to $T$. annulata (KX273857, KT367878), four were 99.89-100\% identical to T. ovis (FJ603460), three were $99.04 \%$ identical to T. equi (KY952232), one was $99.25 \%$ identical to T. buffeli (HM538197) and one was $99.35 \%$ identical to B. bovis (EF601930) (Table 2). The phylogenetic position of Piroplasmida identified in our study is illustrated in Fig. 2.

Similarly, three $R h$. annulatus, one $R h$. sanguineus s.l., one $R h$. bursa and nine blood samples were positive for Anaplasma spp. The sequences obtained from Rh. sanguineus s.l. and Rh. bursa were $100 \%$ identical to A. ovis (KY498325). Two of the three sequences obtained from $R h$. annulatus were $98.07 \%$ identical to "Candidatus Ehrlichia urmitei" (KM021422) and one was $97.69 \%$, identical to A. platys (KM021414). In animals, four sequences were $99.57-100 \%$ identical to $A$. marginale (CP006847, KY498335) and five were 99.5-100\% identical to A. ovis (KM021411) (Table 2). The phylogenetic tree based on the 23S gene (485 bp) shows the position of the Anaplasmatacae genotypes of this study compared to the other genotypes in Supplementary Fig. 1.

Rickettsia massiliae was identified in two Rh. sanguineus s.l. and two Rh. bursa and R. aeschlimannii in two Hy. scupense, one Hy. impeltatum and one Hy. marginatum by specific qPCR. The sequencing of three ticks which were positive using pan-rickettsial qPCR and negative using specific qPCR allowed us to obtain a sequence only from $R h$. bursa, which was 99.28 \% identical to "Candidatus Rickettsia barbariae" (KU645284). All blood samples were negative for Rickettsia spp. (Table 2).

All tested ticks were negative for Borrelia spp. using qPCR. Three blood samples were positive for Borrelia spp. and sequencing showed that the sequences were $99.5 \%$ identical to "uncultured Borrelia sp." detected in Haemaphysalis megaspinosa and Haemaphysalis japonica from Japan (LC170035 and AB897891). The phylogenetic tree based on the 16S rRNA gene (1355 bp) shows the position of the Borrelia sp. of this study compared to the other Borrelia spp. in Supplementary Fig. 2.

All tested samples were found to be negative for $C$. burnetii and Bartonella spp. (Table 2).

\section{Discussion}

In this study we detected the presence of several pathogens in domestic animals and their infesting ticks using robust molecular approaches including appropriate controls. T. equi is an obligate haemoparasite transmitted by ticks that can cause equine piroplasmosis characterised by fever, anaemia, jaundice, hepatosplenomegaly, intravascular haemolysis and haemoglobinuria, or even death (Malekifard et al., 2014). In this study, T. equi was detected in blood of cattle and equids for the first time in Algeria. In Africa, T. equi had been detected in Tunisia (Ros-García et al., 2013), Kenya (Hawkins et al., 2015), Egypt (Mahmoud et al., 2016), Nigeria (Adamu et al., 2014) and South Africa (Rosa et al., 2014). T. annulata is an obligate intracellular protozoan parasite infecting monocytes/macrophages and B cells (Glass et al., 1989). Here, T. annulata was identified in Rh. annulatus ticks and in the blood of cattle and sheep. The presence of T. annulata in cattle was previously detected in eastern and northern central Algeria, in Egypt, Ethiopia, Tunisia and Sudan (Elsify et al., 2015; Gebrekidan et al., 2014; M'ghirbi et al., 2008; Taha et al., 2013; Ziam and Benaouf, 2004; Ziam et al., 2015). Theileria buffeli is known as a widely distributed benign haemoparasite of cattle usually transmitted by Hae. punctata ticks throughout the Mediterranean basin (Grech-Angelini et al., 2016). In our study, T. buffeli was detected in cattle and $R h$. annulatus ticks. T. buffeli was reported for the first time in Algeria by 


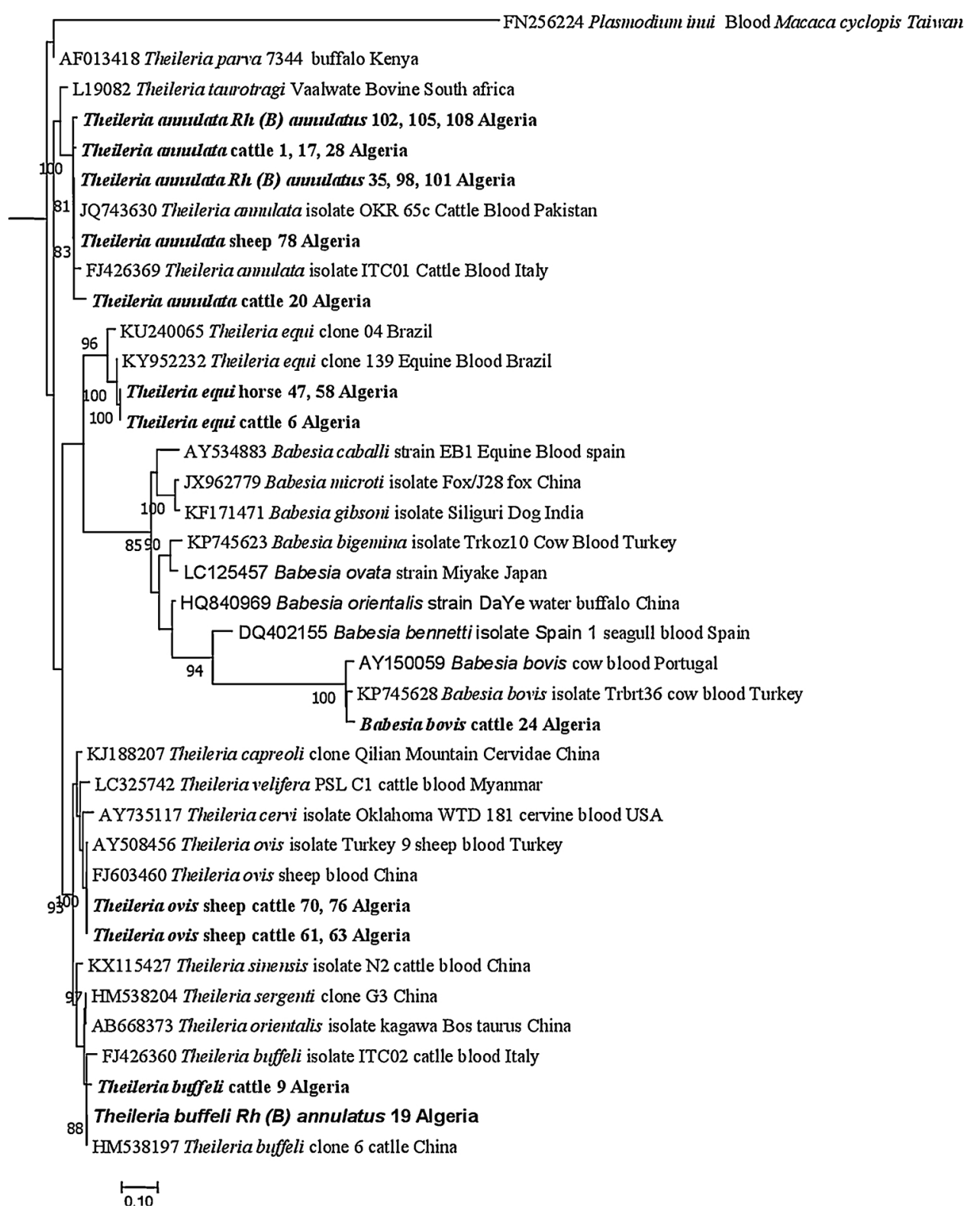

Fig. 2. Phylogenetic tree showing the relationships between Piroplasmida identified in the present study relative to other species based on a comparison of a 965 bp fragment of the $18 \mathrm{~S}$ gene.

Ziam et al. (2015). It has also been found in cattle from Tunisia (M'ghirbi et al., 2008) and in buffalo from South Africa and Mozambique (Chaisi et al., 2013). T. ovis was detected only in sheep, in line with previous studies reporting the detection of this pathogen in sheep, goats and Rhipicephalus ticks in Algeria (Aouadi et al., 2017). It is a causative agent of subclinical infection in small ruminants and is widespread throughout in the world (Jalali et al., 2014).

B. bovis, the agent responsible for bovine babesiosis, is a highly prevalent protozoan intra-erythrocyte parasite of economic importance in cattle and is transmitted by ticks (Mtshali and Mtshali, 2013). In this study, B. bovis was found in cattle from eastern Algeria, which was consistent with previous results reported by Ziam and Benaouf (2004). It has also been detected in cattle from Kenya (Adjou Moumouni et al., 2015).

In this study, we detected several Anaplasma species, including A. marginale, an obligate intracellular bacterium responsible for bovine anaplasmosis worldwide, manifested by anaemia and jaundice (Parola and Raoult, 2001). As previously reported in Algeria by Ziam and Benaouf (2004), this bacterium was detected in cattle. In addition, we detected $A$. ovis in the blood of small ruminants, $R h$. sanguineus s.l. and Rh. bursa. Previous studies had already reported the presence of $A$. ovis in these ticks (Aouadi et al., 2017; Aubry and Geale, 2011; Dahmani et al., 2017). Anaplasma ovis is the causative agent of anaplasmosis in small ruminants and is known to be transmitted by several tick species (Dumler et al., 2001). Anaplasma ovis has already been reported in small ruminants and ticks from Algeria and Tunisia (Aouadi et al., 2017; Belkahia et al., 2014, 2017; Ben Said et al., 2015) and in ticks from Ethiopia (Teshale et al., 2016). Interestingly, we identified a new Anaplasma genotype close to A. platys, the agent of canine anaplasmosis which exclusively infects platelets and periodically causes deep thrombocytopenia in dogs (Nair et al., 2016), transmitted by Rh. sanguineus s.l. ticks (Sanogo et al., 2003). Strains which are genetically close to $A$. platys have already been reported in cattle and small rumi-nants (Ben Said et al., 2017, 2018) and in camels (Belkahia et al., 2015; Selmi et al., 2019) from Tunisia. Further analyses are needed, to know whether it is specifically A. platys or genetically-related strains. We also found a potential new species of Ehrlichia which is phylogenetically close to "Candidatus Ehrlichia urmitei" in Rh. annulatus. Little is known 
about this species since it was recently detected for the first time in Amblyomma variegatum, Rhipicephalus microplus and Hyalomma truncatum collected from cattle in Côte d'Ivoire (Ehounoud et al., 2016). More recently, it has also been detected in Rh. microplus and $R h$. bursa collected in France and Mali respectively (Dahmani et al., 2017; Diarra et al., 2017).

In this study, R. massiliae was detected in Rh. bursa and Rh. sanguineus s.l., thus confirming its presence in the country. Similarly, in our study, $R$. aeschlimannii DNA was found in Hy. impeltatum, Hy. scupense and Hy. marginatum. In Algeria, previous studies have reported the presence of $R$. aeschlimannii in several tick species of the Hyalomma genus (Bitam et al., 2006, 2009; Djerbouh et al., 2012; Leulmi et al., 2016). Both $R$. massiliae and $R$. aeschlimannii are spotted fever group rickettsial, known to be agents of emerging rickettsioses in humans. "Candidatus Rickettsia barbariae" was also found in one Rh. bursa. This bacterium was first detected in $R h$. sanguineus sensu lato group ticks collected from Italian sheep (Mura et al., 2008). Since then, several studies have reported the presence of "Candidatus Rickettsia barbariae" in ticks and fleas from Europe and Asia (Chochlakis et al., 2012; Socolovschi et al., 2012; Zhao et al., 2016). Our study is the first to report the presence of "Candidatus Rickettsia barbariae" in Africa. The pathogenicity for animals or humans of this bacterium remains unknown.

The spirochaete $B$. theileri, the causative agent of bovine borreliosis in cattle, associated with fever and anaemia (Smith et al., 1985), was detected in two cattle blood samples. In Algeria, this species has been reported in blood from sheep and goats (Aouadi et al., 2017), but no studies have thus far indicated its presence in Algerian cattle. In Africa, $B$. theileri has also been reported in Rhipicephalus geigyi collected from cattle in Mali (McCoy et al., 2014).

\section{Conclusion}

In this study, we reported the presence of numerous pathogens in mammals and their ticks in north-eastern Algeria. Although we contribute towards broadening the knowledge of the repertoire of microorganisms, our results do not show infection status of the region due to the small amount of material collected. Also, it is not possible to draw conclusion on the competence of these vectors/reservoirs, given that these data do not suggest that the tick species mentioned in the document can serve as a competent vector for all detected pathogens. Nevertheless, other studies are needed to show the exact distribution of ticks and to appreciate the extent of the distribution of microorganisms in Algeria.

\section{Acknowledgments}

We thank all the farmers who agreed to participate to our study and the contributors from the various institutions for the collection of field samples and laboratory analysis. This study was supported by the Institut Hospitalo-Universitaire (IHU) Méditerranée Infection, the National Research Agency under the program "Investissements d'avenir », reference ANR-10-IAHU-03, the Région Provence Alpes Côte d'Azur and European funding FEDER PRIMI.

\section{Appendix A. Supplementary data}

Supplementary material related to this article can be found, in the online version, at doi:https://doi.org/10.1016/j.ttbdis.2019.101330.

\section{References}

Adamu, M., Troskie, M., Oshadu, D.O., Malatji, D.P., Penzhorn, B.L., Matjila, P.T., 2014. Occurrence of tick-transmitted pathogens in dogs in Jos, Plateau State, Nigeria. Parasit. Vectors 7, 119.

Adjou, P.F., Aboge, G.O., Terkawi, M.A., Masatani, T., Cao, S., Kamyingkird, K.,
Jirapattharasate, C., Zhou, M., Wang, G., Liu, M., et al., 2015. Molecular detection and characterization of Babesia bovis, Babesia bigemina, Theileria species and Anaplasma marginale isolated from cattle in Kenya. Parasit. Vectors 8, 496.

Aouadi, A., Leulmi, H., Boucheikhchoukh, M., Benakhla, A., Raoult, D., Parola, P., 2017. Molecular evidence of tick-borne hemoprotozoan-parasites (Theileria ovis and Babesia ovis) and bacteria in ticks and blood from small ruminants in Northern Algeria. Comp. Immunol. Microbiol. Infect. Dis. 50, 34-39.

Aubry, P., Geale, D.W., 2011. A review of bovine anaplasmosis. Transbound. Emerg. Dis. $58,1-30$.

Aydin, M.F., Aktas, M., Dumanli, N., 2015. Molecular identification of Theileria and Babesia in ticks collected from sheep and goats in the Black Sea region of Turkey. Parasitol. Res. 114, 65-69.

Belkahia, H., Ben Said, M., El Hamdi, S., Yahiaoui, M., Gharbi, M., Daaloul-Jedidi, M. Mhadhbi, M., Jedidi, M., Darghouth, M.A., Klabi, I., Zribi, L., Messadi, L., 2014. First molecular identification and genetic characterization of Anaplasma ovis in sheep from Tunisia. Small Rumin. Res. 121, 404-410.

Belkahia, H., Ben Said, M., Sayahi, L., Alberti, A., Messadi, L., 2015. Detection of novel strains genetically related to Anaplasma platys in Tunisian one-humped camels (Camelus dromedarius). J. Infect. Dev. Ctries 9, 1117-1125.

Belkahia, H., Ben Said, M., El Mabrouk, N., Saidani, M., Cherni, C., Ben Hassen, M. Bouattour, A., Messadi, L., 2017. Seasonal dynamics, spatial distribution and genetic analysis of Anaplasma species infecting small ruminants from Northern Tunisia. Infect. Genet. Evol. Dis. 54, 66-73.

Ben Said, M., Belkahia, H., Alberti, A., Zobba, R., Bousrih, M., Yahiaoui, M., DaaloulJedidi, M., Mamlouk, A., Gharbi, M., Messadi, L., 2015. Molecular Survey of Anaplasma species in small ruminants reveals the presence of novel strains closely related to A. phagocytophilum in Tunisia. Vector Borne Zoonotic Dis. 15, 580-590.

Ben Said, M., Belkahia, H., El Mabrouk, N., Saidani, M., Alberti, A., Zobba, R., Cherif, A., Mahjoub, T., Bouattour, A., Messadi, L., 2017. Anaplasma platys-like strains in ru-

minants from Tunisia. Infect. Genet. Evol. Dis. 49, 226-233.

Ben Said, M., Belkahia, H., Messadi, L., 2018. Anaplasma spp. in North Africa: a review on molecular epidemiology, associated risk factors and genetic characteristics. Ticks Tick. Dis. 9, 543-555.

Bitam, I., Parola, P., Matsumoto, K., Rolain, J.M., Baziz, B., Boubidi, S.C., Harrat, Z., Belkaid, M., Raoult, D., 2006. First molecular detection of R. conorii, R. aeschlimannii, and R. massiliae in ticks from Algeria. Ann. N. Y. Acad. Sci. 1078, 368-372.

Bitam, I., Kernif, T., Harrat, Z., Parola, P., Raoult, D., 2009. First detection of Rickettsia aeschlimannii in Hyalomma aegyptium from Algeria. Clin. Microbiol. Infect. 2, 253-254.

Boucheikhchoukh, M., Laroche, M., Aouadi, A., Dib, L., Benakhla, A., Raoult, D., Parola, P., 2018. MALDI-TOF MS identification of ticks of domestic and wild animals in Algeria and molecular detection of associated microorganisms. Comp. Immunol. Microbiol. Infect. Dis. 57, 39-49.

Chaisi, M.E., Janssens, M.E., Vermeiren, L., Oosthuizen, M.C., Collins, N.E., Geysen, D., 2013. Evaluation of a real-time PCR test for the detection and discrimination of

theileria species in the African buffalo (Syncerus caffer). PLoS One 8, e75827. Chochlakis, D., Ioannou, I., Sandalakis, V., Dimitriou, T., Kassinis, N., Papadopoulos, B.,

Tselentis, Y., Psaroulaki, A., 2012. Spotted fever group Rickettsiae in ticks in Cyprus. Microb. Ecol. 63, 314-323.

Dahmani, M., Davoust, B., Benterki, M.S., Fenollar, F., Raoult, D., Mediannikov, O., 2015 Development of a new PCR-based assay to detect Anaplasmataceae and the first report of Anaplasma phagocytophilum and Anaplasma platys in cattle from Algeria. Comp. Immunol. Microbiol. Infect. Dis. 39, 39-45.

Dahmani, M., Davoust, B., Rousseau, F., Raoult, D., Fenollar, F., Mediannikov, O., 2017. Natural Anaplasmataceae infection in Rhipicephalus bursa ticks collected from sheep in the French Basque Country. Ticks Tick-Borne Dis. 8, 18-24.

Diarra, A.Z., Almeras, L., Laroche, M., Berenger, J.-M., Koné, A.K., Bocoum, Z., Dabo, A., Doumbo, O., Raoult, D., Parola, P., 2017. Molecular and MALDI-TOF identification of ticks and tick-associated bacteria in Mali. PLoS Negl. Trop. Dis. 11, e0005762.

Dib, L., Bitam, I., Tahri, M., Bensouilah, M., De Meeûs, T., 2008. Competitive exclusion between piroplasmosis and anaplasmosis agents within cattle. PLoS Pathog. 4, e7.

Djerbouh, A., Kernif, T., Beneldjouzi, A., Socolovschi, C., Kechemir, N., Parola, P., Raoult, D., Bitam, I., 2012. The first molecular detection of Rickettsia aeschlimannii in the ticks of camels from southern Algeria. Ticks Tick-Borne Dis. 3, 374-376.

Dumler, J.S., Barbet, A.F., Bekker, C.P., Dasch, G.A., Palmer, G.H., Ray, S.C., Rikihisa, Y., Rurangirwa, F.R., 2001. Reorganization of genera in the families Rickettsiaceae and Anaplasmataceae in the order Rickettsiales: unification of some species of Ehrlichia with Anaplasma, Cowdria with Ehrlichia and Ehrlichia with Neorickettsia, descriptions of six new species combinations and designation of Ehrlichia equi and "HGE agent" as subjective synonyms of Ehrlichia phagocytophila. Int. J. Syst. Evol. Microbiol. 51, 2145-2165.

Ehounoud, C.B., Yao, K.P., Dahmani, M., Achi, Y.L., Amanzougaghene, N., Kacou N'Douba, A., N'Guessan, J.D., Raoult, D., Fenollar, F., Mediannikov, O., 2016 Correction: multiple pathogens including potential new species in tick vectors in côte d'Ivoire. PLoS Negl. Trop. Dis. 10, e0004455.

Elsify, A., Sivakumar, T., Nayel, M., Salama, A., Elkhtam, A., Rizk, M., Mosaab, O., Sultan, K., Elsayed, S., Igarashi, I., et al., 2015. An epidemiological survey of bovine Babesia and Theileria parasites in cattle, buffaloes, and sheep in Egypt. Parasitol. Int. 64, 7985.

Gebrekidan, H., Hailu, A., Kassahun, A., Rohoušová, I., Maia, C., Talmi-Frank, D., Warburg, A., Baneth, G., 2014. Theileria infection in domestic ruminants in northern Ethiopia. Vet. Parasitol. 200, 31-38.

Glass, E.J., Innes, E.A., Spooner, R.L., Brown, C.G., 1989. Infection of bovine monocyte/ macrophage populations with Theileria annulata and Theileria parva. Vet. Immunol. Immunopathol. 22, 355-368.

Grech-Angelini, S., Stachurski, F., Lancelot, R., Boissier, J., Allienne, J.-F., Marco, S., 
Maestrini, O., Uilenberg, G., 2016. Ticks (Acari: Ixodidae) infesting cattle and some other domestic and wild hosts on the French Mediterranean island of Corsica. Parasit. Vectors 9, 582.

Hawkins, E., Kock, R., McKeever, D., Gakuya, F., Musyoki, C., Chege, S.M., Mutinda, M., Kariuki, E., Davidson, Z., Low, B., et al., 2015. Prevalence of Theileria equi and Babesia caballi as well as the identification of associated ticks in sympatric Grevy's zebras (Equus grevyi) and donkeys (Equus africanus asinus) in northern Kenya. J. Wildl. Dis. 51, 137-147.

Jalali, S.M., Khaki, Z., Kazemi, B., Rahbari, S., Shayan, P., Bandehpour, M., Yasini, S.P., 2014. Molecular detection and identification of Theileria species by PCR-RFLP 339Method in sheep from Ahvaz, Southern Iran. Iran. J. Parasitol. 9, 99-106.

Kernif, T., Socolovschi, C., Bitam, I., Raoult, D., Parola, P., 2012. Vector-borne rickettsioses in North Africa. Infect. Dis. Clin. North Am. 26, 455-478.

Leulmi, H., Aouadi, A., Bitam, I., Bessas, A., Benakhla, A., Raoult, D., Parola, P., 2016.

Detection of Bartonella tamiae, Coxiella burnetii and rickettsiae in arthropods and tis-sues from wild and domestic animals in northeastern Algeria. Parasit. Vectors 9, 27.

Mahmoud, M.S., El-Ezz, N.T.A., Abdel-Shafy, S., Nassar, S.A., El Namaky, A.H., Khalil, W.K.B., Knowles, D., Kappmeyer, L., Silva, M.G., Suarez, C.E., 2016. Assessment of Theileria equi and Babesia caballi infections in equine populations in Egypt by molecular, serological and hematological approaches. Parasit. Vectors 9, 260.

Malekifard, F., Tavassoli, M., Yakhchali, M., Darvishzadeh, R., 2014. Detection of Theileria equi and Babesia caballi using microscopic and molecular methods in horses

in suburb of Urmia, Iran. Vet. Res. Forum Int. Q. J. 5, 129-133.

McCoy, B.N., Maïga, O., Schwan, T.G., 2014. Detection of Borrelia theileri in Rhipicephalus geigyi from Mali. Ticks Tick-Borne Dis. 5, 401-403.

M'ghirbi, Y., Hurtado, A., Barandika, J.F., Brandika, J., Khlif, K., Ketata, Z., Bouattour, A., 2008. A molecular survey of Theileria and Babesia parasites in cattle, with a note on the distribution of ticks in Tunisia. Parasitol. Res. 103, 435-442.

Mtshali, M.S., Mtshali, P.S., 2013. Molecular diagnosis and phylogenetic analysis of Babesia bigemina and Babesia bovis hemoparasites from cattle in South Africa. BMC Vet. Res. 9, 154.

Mura, A., Masala, G., Tola, S., Satta, G., Fois, F., Piras, P., Rolain, J.-M., Raoult, D., Parola, P., 2008. First direct detection of rickettsial pathogens and a new rickettsia, "Candidatus Rickettsia barbariae", in ticks from Sardinia, Italy. Clin. Microbiol. Infect. $14,1028-1033$.

Nair, A.D.S., Cheng, C., Ganta, C.K., Sanderson, M.W., Alleman, A.R., Munderloh, U.G., Ganta, R.R., 2016. Comparative Experimental Infection Study in Dogs with Ehrlichia canis, E. chaffeensis, Anaplasma platys and A. phagocytophilum. PLoS One 11, e0148239.

Parola, P., Raoult, D., 2001. Molecular tools in the epidemiology of tick-borne bacterial diseases. Ann. Biol. Clin. (Paris) 59, 177-182.

Pereira, A., Parreira, R., Nunes, M., Casadinho, A., Vieira, M.L., Campino, L., Maia, C., 2016. Molecular detection of tick-borne bacteria and protozoa in cervids and wild boars from Portugal. Parasit. Vectors 9, 251.

Remedio, R.N., Nunes, P.H., Anholeto, L.A., Oliveira, P.R., Camargo-Mathias, M.I., 2015. Morphological effects of neem (Azadirachta indica A. Juss) seed oil with known azadirachtin concentrations on the oocytes of semi-engorged Rhipicephalus sanguineus ticks (Acari: Ixodidae). Parasitol. Res. 114, 431-444.
Rjeibi, M.R., Amairia, S., Rouatbi, M., Ben Salem, F., Mabrouk, M., Gharbi, M., 2016. Molecular prevalence and genetic characterization of piroplasms in dogs from Tunisia. Parasitology 143, 1622-1628.

Rosa, C.T., Pazzi, P., Nagel, S., McClure, V., Christie, J., Troskie, M., Dvir, E., 2014 Theileriosis in six dogs in South Africa and its potential clinical significance. J. S. Afr. Vet. Assoc. 85, 1114.

Ros-García, A., M'ghirbi, Y., Hurtado, A., Bouattour, A., 2013. Prevalence and genetic diversity of piroplasm species in horses and ticks from Tunisia. Infect. Genet. Evol. J. Mol. Epidemiol. Evol. Genet. Infect. Dis. 17, 33-37.

Sanogo, Y.O., Davoust, B., Inokuma, H., Camicas, J.-L., Parola, P., Brouqui, P., 2003. First evidence of Anaplasma platys in Rhipicephalus sanguineus (Acari: Ixodida) collected from dogs in Africa. Onderstepoort J. Vet. Res. 70, 205-212.

Selmi, R., Ben Said, M., Dhibi, M., Ben Yahia, H., Messadi, L., 2019. Improving specific detection and updating phylogenetic data related to Anaplasma platys-like strains infecting camels (Camelus dromedarius) and their ticks. Ticks Tick. Dis. 10, 101260.

Smith, R.D., Miranpuri, G.S., Adams, J.H., Ahrens, E.H., 1985. Borrelia theileri: isolation from ticks (Boophilus microplus) and tick-borne transmission between splenectomized calves. Am. J. Vet. Res. 46, 1396-1398.

Socolovschi, C., Reynaud, P., Kernif, T., Raoult, D., Parola, P., 2012. Rickettsiae of spotted fever group, Borrelia valaisiana, and Coxiella burnetii in ticks on passerine birds and mammals from the Camargue in the south of France. Ticks Tick-Borne Dis. 3, 355360

Taha, K.M., Salih, D.A., Ali, A.M., Omer, R.A., El Hussein, A.M., 2013. Naturally occurring infections of cattle with Theileria lestoquardi and sheep with Theileria annulata in the Sudan. Vet. Parasitol. 191, 143-145.

Tahir, D., Socolovschi, C., Marié, J.-L., Ganay, G., Berenger, J.-M., Bompar, J.-M., Blanchet, D., Cheuret, M., Mediannikov, O., Raoult, D., et al., 2016. New Rickettsia species in soft ticks Ornithodoros hasei collected from bats in French Guiana. Ticks Tick-Borne Dis. 7, 1089-1096.

Teshale, S., Kumsa, B., Menandro, M.L., Cassini, R., Martini, M., 2016. Anaplasma, Ehrlichia and rickettsial pathogens in ixodid ticks infesting cattle and sheep in western Oromia, Ethiopia. Exp. Appl. Acarol. 70, 231-237.

Toma, L., Di Luca, M., Mancini, F., Severini, F., Mariano, C., Nicolai, G., Laghezza Masci, V., Ciervo, A., Fausto, A.M., Cacciò, S.M., 2017. Molecular characterization of Babesia and Theileria species in ticks collected in the outskirt of Monte Romano, Lazio Region, Central Italy. Ann. Ist. Super. Sanita 53, 30-34.

Walker, A., 2003. Ticks of Domestic Animals in Africa: a Guide to Identification of Species (Edinburgh: Bioscience Reports).

Zhao, S.S., Li, H.Y., Yin, X.P., Liu, Z.Q., Chen, C.F., Wang, Y.Z., 2016. First detection of Candidatus Rickettsia barbariae in the flea Vermipsylla alakurt from north-western China. Parasit. Vectors 9, 325.

Ziam, H., Benaouf, H., 2004. Prevalence of blood parasites in cattle from wilayates of Annaba and El Tarf east Algeria. Arch. Inst. Pasteur Tunis 81, 27-30. Ziam, H., Kelanamer, R., Aissi, M., Ababou, A., Berkvens, D., Geysen, D., 2015. Prevalence of bovine theileriosis in North Central region of Algeria by real-time polymerase chain reaction with a note on its distribution. Trop. Anim. Health Prod. 47, 787-796. 